\title{
Autoantibody production in chronic idiopathic urticaria is not associated with Helicobacter pylori infection
}

\author{
A.M. Atta ${ }^{1}$, \\ M.Z.A. Rodrigues ${ }^{2}$, \\ C.P. Sousa ${ }^{2}$, \\ M. Medeiros Júnior ${ }^{3}$ \\ and M.L.B. Sousa-Atta ${ }^{1}$
}

\author{
1Departamento de Análises Clínicas e Toxicológicas, \\ ${ }^{2}$ Programa de Pós-Graduação em Imunologia, \\ Instituto de Ciências da Saúde, and 'Serviço de Imunologia, \\ Hospital Universitário Professor Edgard Santos, \\ Universidade Federal da Bahia, Salvador, BA, Brasil
}

\author{
Correspondence \\ A.M. Atta \\ Departamento de Análises Clínicas \\ e Toxicológicas \\ Faculdade de Farmácia, UFBA \\ Rua Barão de Geremoabo s/n \\ Campus Ondina \\ 40171-970 Salvador, BA \\ Brasil \\ Fax: +55-71-354-3855 \\ E-mail: ajatta@ig.com.br \\ $\ldots \ldots \ldots \ldots \ldots \ldots \ldots$
}

Received May 9, 2003

Accepted October 10, 2003

\begin{abstract}
Chronic idiopathic urticaria (CIU) is a dermatological syndrome, characterized by raised erythematous skin lesions, that affects $20 \%$ of the general population and has been associated with autoimmunity. However, some reports have also suggested a close relationship between CIU and Helicobacter pylori infection, which is endemic in developing countries and associated with chronic gastritis, peptic ulcer disease, and gastric carcinoma. In the present study, we investigated the occurrence of autoantibodies in sera from 23 CIU subjects infected with $H$. pylori and from $23 \mathrm{CIU}$ subjects without this infection. The presence of anti-thyroid antibodies was determined by indirect hemagglutination assay and the presence of autoantibodies to $\mathrm{IgE}$ and $\mathrm{C} 1 \mathrm{INH}$ was determined by ELISA. Antibodies to thyroid antigens were detected at low titers from 100 to 400 in three of 23 (13\%) CIU-infected subjects and in four of $23(17 \%)$ CIU-noninfected subjects. The titers of anti-IgE autoantibodies were similar in these CIU groups, presenting absorbances of $1.16 \pm 0.09$ and $1.07 \pm 0.16$, respectively, while a titer of $1.14 \pm 0.15$ was detected in the healthy control group. The concentration of anti-C1INH autoantibodies was the same in the CIU-infected and -noninfected subjects $(7.28 \pm 1.31$ and $7.91 \pm 2.45 \mathrm{ng} / \mathrm{ml}$, respectively), and was $7.20 \pm 2.25 \mathrm{ng} / \mathrm{ml}$ in the healthy control group. However, the serum levels of complexed anti$\mathrm{C} 1 \mathrm{INH}$ antibodies were increased in CIU-infected subjects compared to CIU-noninfected subjects and healthy controls with an absorbance of $1.51 \pm 0.21$ vs $1.36 \pm 0.16$ and $1.26 \pm 0.23$, respectively $(\mathrm{P}<0.05)$, indicating an impaired clearance of immune complexes in CIUinfected patients. In conclusion, no correlation was observed between H. pylori infection and autoantibody production in CIU patients consistent with reports of clinical studies.
\end{abstract}

Key words

- Chronic idiopathic urticaria

- Autoimmunity

- Autoantibodies

- Helicobacter pylori 
Urticaria is a common syndrome that affects $20 \%$ of the general population, clinically characterized by the sudden appearance of raised erythematous skin lesions at different sites which are usually pruritic and then tend to disappear (1). Urticaria is classified as chronic idiopathic (CIU) when the cutaneous wheals occur daily or almost daily and persist for more than six weeks, followed by spontaneous remission. The etiology of CIU is unknown (2).

In recent years, different research groups have investigated the involvement of autoimmune mechanisms in CIU, obtaining strong evidence of the participation of different pathogenic autoantibodies. Histaminereleasing autoantibodies that react with $\operatorname{IgE}$ epitopes, or are more frequently produced against the $\alpha$-chain of the high affinity $\operatorname{IgE}$ receptor of mast cells and basophils (FceRI), have been detected in CIU patients by the autologous serum skin test and by immunoassay $(3,4)$.

Some CIU patients may present angioedema, a reaction closely similar to urticaria that occurs in deeper tissues, which may also be observed as an isolated clinical event (1). This type of angioedema results from an acquired immunological deficiency of C1INH provoked by polyclonal autoantibodies that block the reactive center of this serpin, facilitating its digestion by activated $\mathrm{C} 1 \mathrm{r}$ and $\mathrm{C} 1 \mathrm{~s}$ (5). As a consequence, there is an uncontrolled activation of complement and also of all the enzyme systems activated by the Hageman factor and its fragments, such as the clotting system and the kiningenerating system, causing overproduction of bioactive peptides such as histamine, and also the production and excretion of other pro-inflammatory mediators from mast cells, basophils and platelets (5).

An association of CIU with autoimmune thyroiditis and Helicobacter pylori infection has been suggested by some research groups (6-9). This Gram-negative bacillus, which infects almost $70 \%$ of the population of de- veloping countries such as Brazil, causes chronic gastritis and peptic ulcer disease, being also an important risk factor for gastric carcinoma (10).

More recently, it was suggested that $H$. pylori infection might participate in the pathogenesis of acquired angioedema in infected persons due the excessive consumption of complement by specific antibodies produced against the bacterium (11). In addition, chemotherapy for the eradication of $H$. pylori infection seems to contribute significantly to the remission of hereditary angioedema in persons presenting this syndrome (12).

The molecular basis of these associations is unknown, and studies are needed to elucidate the molecular and cellular mechanisms of CIU and angioedema (13). The objective of the present study was to investigate the occurrence of anti-thyroid, anti- $\operatorname{IgE}$ and antiC1INH autoantibodies in sera from CIU patients and to obtain information about the association of this autoimmune response with H. pylori infection.

Forty-six sera from CIU patients, 15 males and 31 females ranging in age from 15 to 76 years, were evaluated in this study. All patients had a clinical diagnosis of CIU, presenting urticarial skin lesions during physical examination, as well as a conclusive history of repeated episodes of urticaria lasting for more than 6 weeks, without an apparent definitive cause. A sporadic episode of angioedema was reported by some of them.

Twenty-three CIU patients seronegative for anti-H. pylori IgG antibodies by DOTELISA (Orgenic, Yavne, Israel) represented the noninfected group, while $23 \mathrm{CIU}$ patients seropositive for the bacterium represented the infected group. The control group consisted of 10 healthy adults of similar age without a clinical history of CIU. All of them had negative laboratory results for Chagas' disease, syphilis, viral hepatitis and chronic diseases such as autoimmune thyroiditis and rheumatoid arthritis.

The following immunologic parameters 
were investigated: anti-IgE IgG autoantibodies, autoantibodies to thyroglobulin and thyroid peroxidase (TPO), IgG autoantibodies to $\mathrm{C} 1 \mathrm{INH}$ and also their respective immune complexes.

Immunocapture ELISA was used to detect anti-IgE IgG autoantibodies (14). Briefly, the polystyrene microwells of an ELISA plate (Maxisorp, Nunc, Roskilde, Denmark) were coated with $500 \mathrm{ng}$ of anti-human IgE goat IgG antibodies (Sigma Chemical Co., St. Louis, MO, USA) and their reactive sites were blocked with $1 \%$ BSA in PBS. The immune reaction for IgE capture was carried out for $1 \mathrm{~h}$ at $37^{\circ} \mathrm{C}$, with $100 \mu \mathrm{l}$ of human serum diluted at 1/20 in PBS containing 1\% BSA and $0.05 \%$ Tween-20.

The detection of human anti-IgE IgG autoantibodies after their primary reaction with IgE captured by goat anti-IgE antibodies was performed with $100 \mu$ l of peroxidase-conjugated goat anti-human IgG (Sigma) over a period of $1 \mathrm{~h}$ at $37^{\circ} \mathrm{C}$, after washing the wells with PBS containing $0.05 \%$ Tween- 20 .

The reactions in the wells were developed with hydrogen peroxide plus 3,3',5,5'tetramethylbenzidine in $100 \mathrm{mM}$ citratephosphate buffer, $\mathrm{pH}$ 5.0, for $30 \mathrm{~min}$, and their absorbances were monitored at 450$600 \mathrm{~nm}$ with a Diamedix BP-12 Microassay apparatus (Miami, FL, USA) after the addition of $50 \mu \mathrm{l}$ of $0.5 \mathrm{~N}$ sulfuric acid.

Autoantibodies to thyroid antigens, TPO and thyroglobulin were investigated by indirect hemagglutination using $\mathrm{M}-$ Immune $^{\mathrm{TM}}$ and T-Immune ${ }^{\mathrm{TM}}$ kits (Murex Biotech Limited, Dartford, Kent, UK), respectively. The titer of the positive reactions is reported as the reciprocal of the highest dilution giving $50 \%$ agglutination.

Serum IgG autoantibodies to C1INH were investigated by indirect ELISA in polystyrene microwells coated with $500 \mathrm{ng}$ purified C1INH (Sigma) (15). The modifications introduced in this assay were the use of PBS containing 1\% BSA to block reactive sites on the solid phase and replacement of $o$-phenylenediamine with 3,3',5,5'-tetramethylbenzidine in the substrate.

The relative concentration of serum antiC1INH IgG in this test was determined arbitrarily using a reference curve obtained by indirect ELISA carried out in wells coated with $500 \mathrm{ng} \mathrm{C} 1 \mathrm{INH}$, using both goat antiserum to human C1INH (Sigma, lot: 119H4837, $1.9 \mathrm{mg} / \mathrm{ml}$ specific antibody) and peroxidase-conjugated anti-goat IgG rabbit IgG purchased from the same source.

Serum immune complexes of anti-C1INH autoantibodies were investigated by immunocapture ELISA using polystyrene microwells coated with goat anti-human C1INH antibody (15). Peroxidase-conjugated antihuman $\operatorname{IgG}$ goat $\operatorname{IgG}$ was used to visualize the captured autoantibody.

The results obtained in the immunoassays are reported as means $\pm \mathrm{SD}$. Data were analyzed statistically by the Kruskal-Wallis nonparametric test, with the level of significance set at $\mathrm{P}<0.05$.

Autoantibodies to thyroid antigens were detected at low titers ranging from 100 to 400 in the two CIU groups. Anti-thyroglobulin antibodies were observed in two of 23 sera from CIU patients seropositive for $H$. pylori infection, and in only one serum from the noninfected CIU group. Anti-TPO autoantibodies were also observed at low titers in three of $23(13 \%)$ and in two of 23 sera from these two groups of CIU patients, respectively.

Anti-IgE $\operatorname{IgG}$ autoantibody titers were similar in the groups evaluated. Sera from CIU patients infected with $H$. pylori presented a mean absorbance of $1.16 \pm 0.09$, while values of $1.07 \pm 0.16$ and of $1.14 \pm$ 0.15 were observed with sera from CIUnoninfected subjects and from healthy controls, respectively.

There was no difference in the serum concentration of anti-C1INH antibodies among the three groups studied. A concentration of $7.28 \pm 1.31 \mathrm{ng}$ antibody/ml was observed in the sera from CIU-infected pa- 
tients, while a concentration of $7.91 \pm 2.45$ and of $7.20 \pm 2.25 \mathrm{ng}$ antibody $/ \mathrm{ml}$ was detected in sera from CIU-noninfected subjects and from healthy controls, respectively.

On the other hand, increased levels of circulating immune complexes of antiC1INH antibodies were detected in sera from CIU patients infected with $H$. pylori. This group presented a mean absorbance of 1.51 \pm 0.21 , while CIU-noninfected subjects and healthy controls showed absorbances of 1.36 \pm 0.16 and $1.26 \pm 0.23$, respectively (Figure $1)$.

In the present study we assessed some autoimmune aspects of CIU patients and specifically investigated a possible relationship between $H$. pylori infection and production of anti-thyroid, anti-IgE and anti-C1INH autoantibodies.

The prevalence of serum anti-TPO autoantibodies observed in both CIU patient groups differed from that reported for the general population, which is $3-6 \%$ (16). A similar increased seroprevalence of anti-TPO

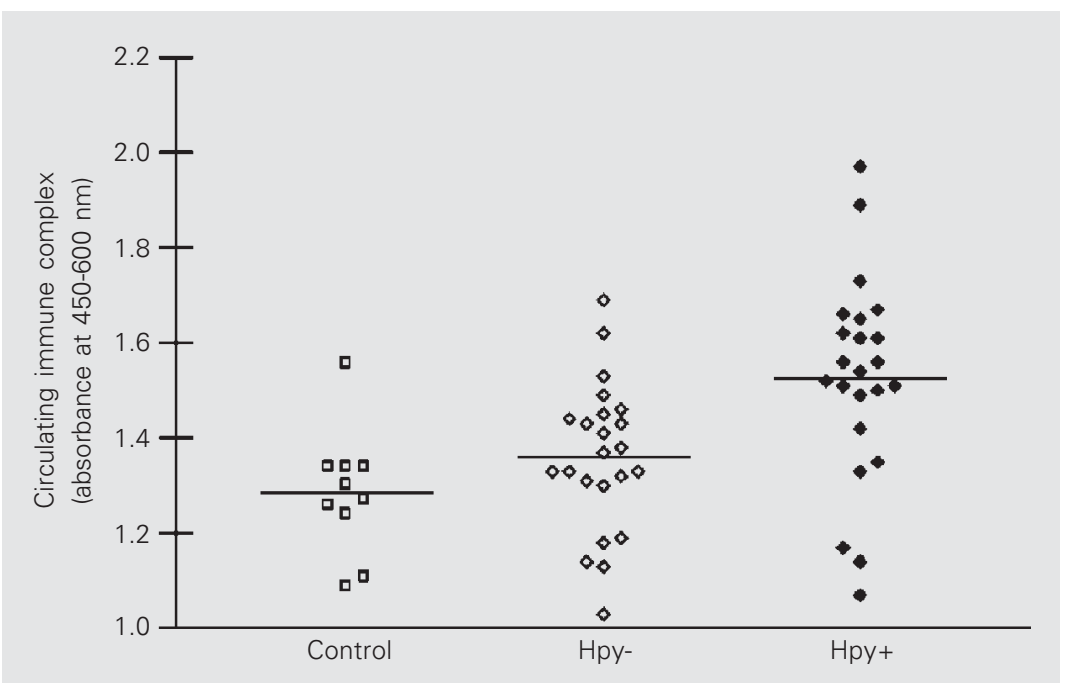

Figure 1. Serum levels of circulating immune complexes of anti-C1INH IgG autoantibodies as determined by immunocapture ELISA using goat anti-human $\mathrm{C} 1 \mathrm{INH}$ and peroxidaseconjugated goat anti-human $\mathrm{lgG}$. Circulating immune complex levels are reported as absorbance at $450-600 \mathrm{~nm}$. Sera from the following groups were evaluated: healthy controls $(\mathrm{N}=10$ ), $\mathrm{ClU}$ patients without $\mathrm{H}$. pylori infection (Hpy-, $\mathrm{N}=23$ ), and $\mathrm{ClU}$ patients with $H$. pylori infection (Hpy+, $N=23)$. Different circulating immune complex levels were demonstrated in the three groups by the Kruskal-Wallis test $(P<0.05)$. autoantibodies was also reported in a recent American study carried out on 25 CIU patients (17).

There was no significant difference in serum levels of anti-IgE IgG antibodies between the two groups, as demonstrated by ELISA. Although this test is based on $\operatorname{IgE}$ capture, it measures the serum concentration of free anti- $\operatorname{IgE}$ antibodies, which need a structural modification in the IgE molecule to bind to specific $\varepsilon$-chain epitopes (18). These results agree with previous studies on CIU patients, which were unable to demonstrate any important biological role of antiIgE IgG autoantibodies in the immune mechanism of histamine release $(4,19)$.

Although, no difference in serum concentration of anti-C1INH IgG autoantibodies was observed between the two groups of sera evaluated, excluding the involvement of complement-generated anaphylatoxins in the immune mechanism of histamine release, the levels of anti-C1INH immune complexes were increased in sera from CIU patients infected with $H$. pylori.

At present, we do not known the role of circulating immune complexes of anti$\mathrm{C} 1 \mathrm{INH}$ autoantibodies in the clinical manifestations of CIU in patients infected with $H$. pylori or the mechanisms involved in their persistence in serum. However, the finding of increased levels of anti-C1INH immune complexes in CIU patients infected with $H$. pylori may be a consequence of the impairment of phagocytosis during $H$. pylori infection (20).

In conclusion, in the present study we did not observe any correlation between $H$. pylori infection and autoantibody production in CIU patients using direct measurement of serum antibodies. Similar conclusions were also reported as the result of indirect therapeutic studies, which were unable to show any relationship between $H$. pylori infection and the course of CIU (13). 


\section{References}

1. Metzger WJ (1997). Urticaria, angioedema and hereditary angioedema. In: Pattersen R, Grammer LC \& Greenberger PA (Editors), Allergic Diseases, Diagnosis and Management. LippincottRaven Publishers, Philadelphia, PA, USA, 265-283.

2. Greaves MW (1995). Chronic urticaria. New England Journal of Medicine, 332: 1767-1772.

3. Asero R, Tedeschi A, Lorini M, Salimbeni R, Zanolleti T \& Miadona A (2001). Chronic urticaria: novel clinical and serological aspects. Clinical and Experimental Allergy, 31: 1105-1110.

4. Sabroe RA, Fiebiger E, Francis DM, Maurer D, Seed PT, Grattan CEH, Black AK, Stingl G, Greaves MW \& Barr RM (2002). Classification of anti-FceRI and anti-IgE autoantibodies in chronic idiopathic urticaria and correlation with disease severity. Journal of Allergy and Clinical Immunology, 110: 492-499.

5. Trouw LA, Roos A \& Daha MR (2001). Autoantibodies to complement components. Molecular Immunology, 38: 199-206.

6. Leznoff A \& Sussman GL (1989). Syndrome of idiopathic chronic urticaria and angioedema with thyroid autoimmunity: a study in 90 patients. Journal of Allergy and Clinical Immunology, 84: 66-71.

7. Tuktas I, Gokcora N, Demirsoy S, Cakir N \& Onal E (1997). The association of chronic urticaria and angioedema with autoimmune thyroiditis. International Journal of Dermatology, 36: 187-190.

8. Hizal M, Tüzün B, Wolf $R$ \& Tüzün $Y$ (2000). The relationship between Helicobacter pylori antibody and autologous serum test in chronic urticaria. International Journal of Dermatology, 39: 443-445.

9. Wedi B \& Kapp A (2002). Helicobacter pylori infection in skin diseases: a critical appraisal. American Journal of Clinical Dermatology, 3: 273-282.

10. Dunn BE, Cohen H \& Blaser MJ (1997). Helicobacter pylori. Clinical Microbiology Reviews, 10: 720-741.

11. Farkas H, Gyveney L, Majthéney P, Fust G \& Varga L (1999). Angioedema due to acquired $\mathrm{C} 1$-esterase inhibitor deficiency in a patient with Helicobacter pylori infection. Zeitschrift für Gastroenterologie, 37: 513-518.

12. Farkas H, Fust G, Fekete B, Karádi I \& Varga L (2001). Eradication of Helicobacter pylori and improvement of hereditary angioneurotic oedema. Lancet, 358: 1695-1696.

13. Greaves MW (2001). Chronic idiopathic urticaria (CIU) and Helicobacter pylori - Not directly causative, but could there be a link. Allergy and Clinical Immunology International, 13: 23-26.

14. Atta AM, Sousa-Atta MLB, D'Oliveira A, Almeida RP, Araújo MI \& Carvalho EM (2002). IgG anti-lgE autoantibodies in visceral leishmaniasis. Memórias do Instituto Oswaldo Cruz, 97: 101-103.

15. Giclas PC \& Wisniesky J (1997). Autoantibodies to complement components. In: Rose NR, Macario EC, Folds JD, Lane HC \& Nakamura RM (Editors), Manual of Clinical Laboratory Immunology. ASM Press, Washington, DC, USA, 960-967.

16. Tunbridge WM, Evered DC, Hall R, Appleton D, Brewis M, Clark F, Evans JG, Young E, Bird T \& Smith PA (1977). The spectrum of thyroid disease in a community: the Whickham survey. Clinical Endocrinology, 7: 481-493.

17. Rhyal B, DeMera RS, Shoenfeld Y, Peter JB \& Gershwin ME (2001). Are autoantibodies present in subacute and chronic urticaria? Journal of Investigational Allergology and Clinical Immunology, 11: 1620.

18. Boluda L \& Berrens L (1995). Do IgE-lgG complexes occur in the circulation? Clinical and Experimental Immunology, 100: 145-150.

19. Tong LJ, Balakrishnan G, Kochan JP, Kinét JP \& Kaplan AP (1997). Assessment of autoimmunity in patients with chronic urticaria. Journal of Allergy and Clinical Immunology, 99: 461-465.

20. Ramarao N, Gray-Owen SD, Backert S \& Meyer TF (2000). Helicobacter pylori inhibits phagocytosis by professional phagocytes involving type IV secretion components. Molecular Microbiology, 37: 1389-1404. 